\title{
High wear resistance white ceramic glaze containing needle like zircon single crystals by the addition of sepiolite $\mathrm{n}-\mathrm{ZrO}_{2}$
}

\author{
R. Pina-Zapardiel ${ }^{1}$, A. Esteban-Cubillo ${ }^{2}$, J. F. Bartolomé ${ }^{1}$, C. Pecharromán ${ }^{1}$, J.S.Moya $^{1}$ \\ ${ }^{1}$ Instituto de Ciencia de Materiales de Madrid, CSIC, Cantoblanco Madrid 28049, Spain \\ ${ }^{2}$ Tolsa S.A. R\&D Department \\ *Author to whom all correspondence should be addressed: \\ e-mail: jbartolo@icmm.csic.es \\ Tel/Fax: + $34913348996 /+34985265574$
}

\begin{abstract}
Sepiolite with homogeneous zirconia nanoparticles distribution has been added to a transparent ceramic glaze to study opacification, mechanical and wear resistance properties. It has been observed that monodispersed zircon single crystals with needlelike shape have been formed in the ceramic glaze. These in-situ zircon single crystals give white color and increase opacification ( $\mathrm{L}=94$ vs $\mathrm{L}=90$ ), mechanical properties (hardness and toughness) and wear resistance by a factor of 4 compared to the commercial crystalline glaze containing a similar fraction of micrometer commercial zircon.
\end{abstract}

Keywords: Ceramic glaze; Nanocomposites; Mechanical properties; Wear resistance; Optical properties 


\section{Introduction}

An economically relevant aspect of the ceramic companies is the optimization and improvement of the opacity as well as mechanical properties (mostly wear resistance) in glazes $^{1-4}$. Specially, a relevant problem of manufacturers is the wear and tear that occurs in glazes ${ }^{5,6}$. To overcome this faulty behaviour, it is customary to introduce particles with higher toughness into the frits to avoid detachment and thus, improving the wear resistance. Presently, one of the most widespread additives in the composition of glazes is the zirconium silicate (zircon) because its relatively low cost (it is a natural silicate) and its performance, such as higher scratch hardness, stability against temperature changes of firing, chemical stability and higher wear resistance, better than other additives traditionally used ${ }^{7}$. Zircon is usually incorporated directly in the formulation of ceramic frits before firing, but it can also be synthesized "in situ" by adding zirconia in the composition of the silica based frit during the thermal treatment. This mineral has a high melting point ${ }^{5,8,9}$ and it is used to increase the wear resistance, impact resistance, thermal shock and chemical attack of the glaze. However, due to rising prices in the market and potential supply problems, the current tendency is to decrease the amount of this substance or even to replace it by other less expensive materials, ${ }^{10-12}$.

Opacification is another highly sought after property in the manufacture of ceramic glazes. Due to its high refractive index, zirconia and milled or micronized zircon are used as opacifier for tile glazes and porcelain enamels ${ }^{13,14}$. Particle size is also a relevant factor to take into account in the opacification of glazes. The smaller the particle size of zircon is, the greater the opacity will be obtained. The fraction of zircon added to the frit to achieve a good opacified level differs according to different authors (8-20 wt.\%) $)^{13,15}$ 
In the present work, metastable tetragonal zirconia phase nanoparticles have been synthesized on sepiolite fibers to avoid coalescence and agglomeration.

We propose a new safe method to introduce zirconia nanoparticles in a commercial ceramic frit and to obtain a multifunctional new ceramic glaze with zircon single crystals, which increase the mechanical properties, opacity as well as wear resistance of the original crystalline frit.

\section{Experimental procedure}

Natural sepiolite mineral from Vicalvaro-Vallecas (Tolsa, Spain) has been purified and micronized by a wet process to obtain a final product more than $95 \%$ content of sepiolite. The sepiolite needle-like particles have a length ranging from 0.2 to $2 \mu \mathrm{m}$ and a thickness of 20-100 nm. Structural channels of $0.5 \mathrm{~nm} \times 1.1 \mathrm{~nm}$ extend all along the long dimension of the fibers. Zirconia nanoparticles were obtained following the synthesis process described in a previous work ${ }^{16}$ using $\mathrm{ZrOCl}_{2} \cdot 8 \mathrm{H}_{2} \mathrm{O}$ as reagent. Nanoparticles were shyntesized adjusting $\mathrm{NaOH}$ to stabilize the $\mathrm{pH}$ of the suspension at $\mathrm{pH} 8$ in order to precipitate the corresponding metal hydroxide into the octahedral position of lixiviated magnesium ${ }^{17}$. The obtained precursor was calcined at $900^{\circ} \mathrm{C}$ for $2 \mathrm{~h}$ in air and the final concentration of zirconia in sepiolite was $50 \mathrm{wt}$. \%. The obtained zirconia nanoparticles remained in a stable tetragonal phase.

The sepiolite- $\mathrm{ZrO}_{2}$ calcined at $900{ }^{\circ} \mathrm{C}$ powder was subsequently mixed with a commercial ceramic frit (15 wt.\%) in an agate mortar. Pellets from the powder were obtained by uniaxial pressing at $50 \mathrm{MPa}$ and were heated at $1220^{\circ}$ for $5 \mathrm{~min}$ to become in a glaze. 
The composition of the frit used was: 66,87 wt. $\% \mathrm{SiO}_{2}, 0,07$ wt. $\% \mathrm{Fe}_{2} \mathrm{O}_{3}, 10,99$ wt. \% $\mathrm{ZnO}, 3$ wt. $\% \mathrm{MgO}, 0,02$ wt. $\% \mathrm{Na}_{2} \mathrm{O}, 5$ wt. $\% \mathrm{Al}_{2} \mathrm{O}_{3}, 1,98$ wt. $\% \mathrm{~K}_{2} \mathrm{O}$, and 11,97 wt.\% $\mathrm{CaO}$.

Commercial frit samples with and without zircon (Zircomin, Colorobia, Spain) were used as reference to study the mechanical, optical and wear behaviour. An equivalent zircon quantity (11 wt.\%) was used taken into account the quantity of zirconia in sepiolite.

Samples have been labelled as follows: Fr for commercial frit, FZr for frit with commercial zircon and FSZr for frit with sepiolite- $\mathrm{ZrO}_{2}$. Solid samples were polished with $1 \mu \mathrm{m}$ abrasive diamond paste, to obtain a flat surface to make the wear test. Wear resistance of materials was studied by using a "ball-on-disk" type wear test under ambient dry conditions in a Microtest tribometer (model MT/60/NI) in conformity with ASTM G99, using alumina balls ${ }^{18-20}$. The applied load $\left(\mathrm{F}_{\mathrm{N}}\right)$ was $6 \mathrm{~N}$ and tests lasted 10 $\mathrm{h}$, which corresponded to a sliding distance $(\mathrm{S})$ of $1500 \mathrm{~m}$. Pellets were introduced in an epoxy resin, and then they were cut into plates to make XRD diffraction. X-ray diffraction patterns were recorded in a Bruker D8 diffractometer using $\mathrm{CuK} \alpha$ radiation. Transmission electron microscopy (TEM) images were taken by a JEOL microscope model FXII operating at $200 \mathrm{Kv}$. Scanning electron microscopy Nova тM NanoSEMFEI Company was used for the observation of microstructures of zircon particles and worn surface of the samples. UV-Vis diffuse reflectance measurement was performed on rough surfaces by a Jasco v-660 (Tokyo, Japan) spectrophotometer with a diffuse reflectance attachment. Reflective index measurements were recorded on optically polished surfaces by an Sopra GES-5E ellipsometer equiped with a spectrometer and a photomultiplier operative in the range from 200 to $850 \mathrm{~nm}$ lightened with a xenon short arc lamp, at an incidence angle of $75^{\circ}$. The Vickers hardness, $\mathrm{H}_{\mathrm{V}}$, of the samples was 
determined by microindentation (Buehler model Micromet 5103) on samples surfaces polished down to 1 micron, applying a $1.96 \mathrm{~N}$ load with an indentation time of $10 \mathrm{~s}$. The magnitude of the Vickers hardness was determined according to,

$$
H_{V}=1.854 \frac{P}{d^{2}}
$$

where $P$ is the applied load $(\mathrm{N})$ and $d$ is the diagonal length $(\mathrm{m})$.

The fracture toughness was also determined by microindentation, but for this specific property, the applied load was $4.9 \mathrm{~N}$ with an indentation time of $10 \mathrm{~s}$. The fracture toughness was calculated using the formula given by Miranzo and Moya ${ }^{21}$

In order to estimate correctly the volume losses, the track profiles were analysed with a surface profilometer (Talysurf CLI 500, Taylor Hobson, Leicester, UK) that maps the surface by putting a stylus in mechanical contact with the sample. The stylus arm has $90^{\circ}$ conisphere diamond styli with $2 \mu \mathrm{m}$ nominal radius tip. The data sampling interval in $\mathrm{X}$ and $\mathrm{Y}$ was $0.5 \mu \mathrm{m}$ and $2.5 \mu \mathrm{m}$ respectively. The resolution (Z) was $32 \mathrm{~nm}$. The profilometer was used to determine the three-dimensional surface topographic maps, so track volumes were estimated and, hence, Eq. (2) could be applied.

$$
W=\frac{\Delta V}{F_{N} S}
$$

Being $\mathrm{W}$ the wear rate $\left(\mathrm{mm}^{3} / \mathrm{Nm}\right), \Delta V$ the volume loss after the tests $\left(\mathrm{mm}^{3}\right), F_{N}$ the applied load (N) and $S$ the sliding distance (m). 


\section{Results}

The X-ray diffraction pattern corresponding to sepiolite powder, sepiolite- $\mathrm{ZrO}_{2}$ and sepiolite- $\mathrm{ZrO}_{2}$ calcined at $900^{\circ} \mathrm{C}$ are shown in Figure 1 . As it can be observed, only sepiolite diffraction peaks (Fig.1a) appear in the sepiolite- $\mathrm{ZrO}_{2}$ precursor sample (Fig.1b). However, when this sample was heated at $900^{\circ} \mathrm{C}$ the $\mathrm{t}-\mathrm{ZrO}_{2}$ diffraction peaks are present (Fig.1c). The peaks corresponding to tetragonal zirconia are quite broad, indicating that zirconia particles have a nanostructured character.

The morphology and the particle size distribution of the samples were studied by TEM. As observed in Fig.2, in the sample heated at $900^{\circ} \mathrm{C}$, the particle size distribution seems to be bimodal, probably due to the high zirconia concentration in the fibers (50 wt. \%), where original $\sim 7 \mathrm{~nm}$ zirconia nanoparticles coexist with large agglomerates $(\sim 20 \mathrm{~nm})$. The X-ray diffraction patterns of the obtained glazes are shown in Fig. 3. As it can be seen in Figure 3a, the Fr sample presents no peaks as it corresponds to glassy phase. In the case of FZr and FSZr samples, zircon peaks appear (Fig. 3b and 3c respectively). The absence of peaks of zirconia (tetragonal or monoclinic phase) indicates that zirconia particles reacted with silica to form zircon during firing. A small amount of calcium silicate (wollastonite) also appears.

The size, shape and distribution of zircon particles can be observed by SEM (Fig. 4). The surface of the samples was previously treated with diluted HF to obtain a clearer morphology of the particles. Figure 4 shows that zircon single crystals formed in situ by introducing sepiolite- $\mathrm{ZrO}_{2}$ in the commercial frit (Fig. 4a-b), have a narrower size distribution than the FZr sample with incorporated commercial zircon (Fig. 4c-d). In contrast with the irregular shape from zircon particles of FZr sample, these particles show a needle-like shape with a dimension of 1-2 $\mu \mathrm{m}$ length and 200-300 nm width. 
Figure 5 shows the surface topography of the three-dimensional wear tracks for all materials studied after sliding against pure alumina ball. From the 3D wear track surface topographies, the corresponding wear rate, was estimated and summarized in Table I. In both Fr (Fig. 5a) and FZr samples (Fig. 5b) the wear track depth is similar, but much higher than in the FSZr sample (Fig. 5c), indicating a higher removed volume. The wear rate of FSZr sample decreases down to four times compared to the wear rate of glaze with commercial zircon (FZr) and commercial frit (Fr) (Fig 5d).

The worn surface of the samples was studied by SEM in order to determine the operating wear mechanism. In Fr (Fig.6a) and FZr (Fig. 6b) samples, pull out and material detachment from glaze were observed in a large area of worn surface. The formation of a large number of cracks and sharp edges can be observed. FSZr sample presented a different worn surface (Fig. 6c). A relatively smooth region was observed and no microcracks or microfractures were found at the contact surface. Moreover, it can be observed a good distribution of zircon particles in the entire surface, which is an important factor affecting the wear rate of this glaze.

In Figure $7 \mathrm{a}$, hardness increases corresponding to the containing $11 \%$ zircon with respect to the crystalline glaze, can be observed. Fr glaze has a Hv value of $5.7 \mathrm{GPa}$, while the hardness value for glaze containing zircon increases up to 6.1 and $6.3 \mathrm{GPa}$ for FZr and FSZr respectively. Toughness value $\left(\mathrm{K}_{\mathrm{IC}}\right)$ also increases with the incorporation of zircon to a glaze. In the particular case of the zircon formed during firing, a higher toughness value and less dispersion in the measures $\left(0.9 \pm 0.09 \mathrm{MPa} . \mathrm{m}^{1 / 2}\right)$ than for the commercial zircon addition case $\left(0.7 \pm 0.18 \mathrm{MPa}^{1 / 2}\right)$ is obtained (Fig $\left.7 \mathrm{~b}\right)$.

The optical properties of the studied samples are reported in Table II. The largest L* value, that represents the brightness or whiteness in CIELAB color space, corresponds with FSZr sample with a value of 94.05 while samples FZr and Fr have values of 90.05 
and 67.71 respectively. Finally, reflective measurements report a notable increase of the reflective index (at $\lambda=500 \mathrm{~nm}$ ) for the FSZr sample $\mathrm{n}=1.5887$ in respect to the one corresponding to transparent frit Fr $n=1.5287$. Just for comparison sake, the refractive index corresponding to frit with zircon $\mathrm{FZr}$ presents a value of $\mathrm{n}=1.573$.

\section{Discussion}

It is well known that a good zircon dispersion improves opacification ${ }^{8,15}$, mechanical properties and wear resistance of the glazes ${ }^{22}$. We have herewith used sepiolite as a carrier to support and disperse zirconia nanoparticles and then to introduce them in a glassy matrix to obtain a glaze. Sepiolite plays an important role in the distribution of the particles and thereby avoids coalescence. Particles are embedded into sepiolite fibers avoiding the growth of particles even at high temperature. Moreover sepiolite provides the required silica to react with zirconia nanoparticles forming dispersed needle-like shaped zircon single crystals network with a homogenous size ${ }^{17}$. This raw material in turn, can be mixed with a frit and thus obtain a good dispersion of particles when sepiolite is dissolved in the glaze. Particles of zirconia react in the firing cycle at $1220^{\circ} \mathrm{C}$ with silica that belong to sepiolite and/or frit, to form zircon with the same distribution as zirconia. The presence of a small fraction of wollastonite and zircon in the glaze can be rationalized considering the $\mathrm{SiO}_{2}-\mathrm{ZrO}_{2}-\mathrm{CaO}$ equilibria diagram ${ }^{23}$ and assuming for simplicity reasons, $\mathrm{Na}_{2} \mathrm{O}, \mathrm{K}_{2} \mathrm{O}, \mathrm{MgO}$, and $\mathrm{ZnO}$ in $\mathrm{CaO}$. Obviously, the real temperature of the peritectic corresponding to cristoballite-zircon-wollastonite of this ternary system $\left(1436^{\circ} \mathrm{C}\right)$ in our multicomponent glaze must be significantly lower. Then, the presence of wollastonite at $1220^{\circ} \mathrm{C}$ is thus feasible. In the case of the $\mathrm{FZr}$ sample, the hardness value also increases with respect to the frit and it was similar to the FSZr sample, 
although the standard deviation is higher. Dispersion is an important factor in hardness, because a bad dispersion would produce a gradient in the hardness values. Similarly, toughness also increases in both, but it increases twice in the case of sample FSZr. This is most likely due to their needle-like shape zircon particles network.

The evolution of the loss volume values corresponding to wear test for Fr and FZr samples suggests that the wear mechanism in both materials seems to be similar. The worn surface shows evidence of cracking and pullout (Fig 6). Oppositely the wear rate and the wear mechanism in the FZr and FSZr samples which have the same amount of zircon are totally different. Better dispersion and needle-like shape zircon single crystal grains in the FSZr sample result in higher values for both toughness and hardness, with a lower statistical dispersion, preventing to a greater extent the formation and propagation of cracks in the material. In this sense, the main operating wear mechanism is abrasion which is consistent with the data obtained from wear rate (Table I). Sample FZr has a higher toughness than crystalline glaze in located areas, but the formation of cracks is not inhibited due to uneven distribution of zircon particles, and thus these are formed and propagated through glass brittle matrix material. Because of this, the formation of microcracks in wear track facilitates the removal of material and therefore increases wear rate with respect to FSZr sample.

Opacification is determined by small particles light scattering. In this regard, Rayleigh scattering regime, which corresponds to particles much smaller than the wavelength is the optimal one. Moreover, this scattering increases with the square power of the refractive index contrast ${ }^{24}$. In this sense, zircon and preferentially zirconia, which have very large refractive indices ( $n=1.94$ and 2.16 respectively) and a small particle size become very efficient scatter centres and consequently good opacification agents. In addition to whitening or opacification, the inclusion of zirconia and zircon particles is 
able to raise the effective refractive index, and consequently the reflection coefficient. Refractive index measurements reported in Table II show that the FSZr sample presents the largest increase of the refractive index in comparison with that of the frit (larger refractive index implies larger reflectivity), which suggests that this opacification method produces zircon and/or zirconia particles perfectly embedded into the glassy frit without bubbles, cracks or any other imperfections which could reduce the effective refractive index,. The CIELAB luminance labelled as $L^{*}$, the parameter which takes into account the diffuse reflecting power, increases for larger values of $n$. FSZr sample presents a very high $L^{*}$ value and better than the commercial containing zircon glazes. Consequently, it can be inferred that Sepiolite- $\mathrm{ZrO}_{2}$ sample introduce a larger added value than the one containing commercial zircon, or even higher than other glazes reported in literature with similar zircon content ${ }^{15,25}$.

\section{Conclusions}

The following conclusions can be drawn:

- It has been proved that by the addition $(15 \mathrm{wt} \%)$ of sepiolite- $\mathrm{nZrO}_{2}(50 \mathrm{wt} \%)$ to a commercial transparent ceramic frit, an arrangement of needle-like zircon single crystal $(\sim 1 \mu \mathrm{m})$ is formed in-situ during the firing cycle at $1220^{\circ} \mathrm{C}$.

- The wear rate of the obtained glaze was found to be $\sim 4$ times lower than the one corresponding to a conventional glaze with a similar fraction $(\sim 11 \mathrm{wt} \%)$ of zircon sand.

- The toughness $\left(\mathrm{K}_{\mathrm{IC}}\right)$ of the obtained glaze $\left(0.9 \pm 0.09 \mathrm{MPa} \cdot \mathrm{m}^{1 / 2}\right)$ was found to be almost twice the one corresponding to commercial transparent one $\left(0.5 \pm 0.08 \mathrm{MPa} \cdot \mathrm{m}^{1 / 2}\right)$.

- The $\mathrm{L}^{*}$ values (opacity) and reflectivity of the obtained glaze was found to be 94 vs 90 for the frit with commercial zircon. 


\section{Acknowledgements}

This research has been supported by the Spanish Ministry of Science and Innovation under project DOMINO (CENIT-2007-1001).

\section{References}

1 Karasu B, Dölekcekic E, Özdemir B. Compositional Modifications to Floor Tile Glazes Opacified with Zircon. British Ceramic Transactions 2001, 100:81-85.

${ }^{2}$ Teixeira S, Bernardin AM. Development of $\mathrm{TiO}_{2}$ white glazes for ceramic tiles. Dyes and Pigments 2009, 80:292-296

${ }^{3}$ Montazerian M, Alizadeh P, Eftekhari Yekta B, Processing and properties of a micaapatite glass-ceramic reinforced with Y-PSZ particles. Journal of the European Ceramic Society 2008, 28:2693-2699.

${ }^{4}$ Bijan Eftekhari Yekta, Parvin Alizadeh, Leila Rezazadeh, Floor tile glass-ceramic glaze for improvement of glaze surface properties. Journal of the European Ceramic Society 2006, 26:3809-3812.

${ }^{5}$ Llusar M, Rodrigues C, Labrincha J, Flores M, Monrós G, Reinforcement of singlefiring ceramic glazes with the addition of polycrystalline tetragonal zirconia (3Y-TZP). Journal of the European Ceramic Society 2002, 22:639-652.

${ }^{6}$ Llusar M, Monrós G, Rodrigues CM, Labrincha JA, Study of Zircon or ZirconiaInduced Opacification of Glazes by Impedance Spectroscopy, Ceramics International 2005, 31:181-188.

${ }^{7}$ Parmelee CW, Ceramic Glazes 3rd Revised edition:C. Books, Boston 1973. 
${ }^{8}$ Castilone RJ, Sriram D, Carty WM, Snyder RL, Crystallization of zircon in stoneware glazes. Journal of the American Ceramic Society, 1999, 82:2819-2824.

${ }^{9}$ Aksel C, The influence of zircon on the mechanical properties and thermal shock behaviour of slip-cast alumina-mullite refractories. Materials Letters 2002, 57:992-997.

${ }^{10}$ Pekkan K, Karasu B, Zircon-free frits suitable for single fast-firing opaque wall tile glazes and their industrial productions. Journal of the European Ceramic Society 2009, 29:1571-1578.

11 Biffi G, Ortelli G, Vincenzini P, Ceramic glazes opacified with $\mathrm{CaTiSiO}_{5}$. Ceramurgia International 1975, 1:34-35.

12 Cavalcante P.M.T., Dondi M., Guarini G., Raimondo M., Baldi G., Colour performance of ceramic nano-pigments. Dyes and Pigments 2009, 80:226-232.

${ }^{13}$ Avgustinik A. I., Cerámica, $2^{\circ}$ ed. Barcelona: Reverte; 1983.

14 Jacobs CWF, Opacifying Crystalline Phases Present in Zirconium-Type Glazes. Journal of the American Ceramic Society 1954, 37:216-220.

${ }^{15}$ Snyders E, Potgieter JH, Nel JT, The upgrading of an inferior grade zircon to superior opacifier for sanitary ware and glazes. The Journal of The South African Institute of Mining and Metallurgy 2005, 105:459-464.

${ }^{16}$ Pecharroman C, Esteban-Cubillo A, Montero I, Moya JS, Aguilar E, Santaren J, Alvarez A, Monodisperse and Corrosion-Resistant Metallic Nanoparticles Embedded into Sepiolite Particles for Optical and Magnetic Applications. Journal of the American Ceramic Society 2006, 89:3043-3049.

${ }^{17}$ Esteban-Cubillo A, Pina-Zapardiel R, Moya JS, Barba MF, Pecharroman C, The role of magnesium on the stability of crystalline sepiolite structure. Journal of the European Ceramic Society 2008, 28:1763-1768. 
18 Rodriguez-Suarez T, Bartolomé JF, Smirnov A, Lopez-Esteban S, Torrecillas R, Moya, JS. Sliding wear behaviour of alumina/nickel nanocomposites processed by a conventional sintering route. Journal of the European Ceramic Society 2011,31:13891395.

19 Rodriguez-Suarez T, Bartolomé JF, Smirnov A, Lopez-Esteban S, Díaz LA, Torrecillas R, Moya JS. Electroconductive Alumina-TiC-Ni nanocomposites obtained by Spark Plasma Sintering. Ceramics International 2011,37:1631-1636.

${ }^{20}$ Rodriguez-Suarez T, Bartolomé JF, Moya JS. Mechanical and Tribological properties of ceramic/metal composites: a review of phenomena spanning from the nanometer to the micrometer length scale. Journal of the European Ceramic Society 2012, 32:38873898.

${ }^{21}$ Miranzo P, JS Moya, Elastic/plastic indentation in ceramics: a fracture toughness determination method, Ceramics International 1984, 10:147-152.

${ }^{22}$ Sánchez E, García-Ten J, Sanz V, Moreno A, Porcelain tile: Almost 30 years of steady scientific-technological evolution, Ceramics International 2010, 36:831-845.

${ }^{23}$ Phase Equilibria Diagrams CD-ROM Database (NIST Standard Reference Database 31), Version 3.4, The American Ceramic Society and the National Institute of Standards and Technology, 2012.

${ }^{24}$ Hulst HC, Light scattering by small particles, New York:Wiley; 1957.

${ }^{25}$ Wilson PJ, Blackburn S, Greenwood RW, Prajapti B, Smalley K, The role of zircon particle size distribution, surface area and contamination on the properties of silicazircon ceramic materials. Journal of the European Ceramic Society 2011, 31:1849-1855. 


\begin{abstract}
Sepiolite with homogeneous zirconia nanoparticles distribution has been added to a transparent ceramic glaze to study opacification, mechanical and wear resistance properties. It has been observed that monodispersed zircon single crystals with needlelike shape have been formed in the ceramic glaze. These in-situ zircon single crystals give white color and increase opacification ( $\mathrm{L}=94$ vs $\mathrm{L}=90)$, mechanical properties (hardness and toughness) and wear resistance by a factor of 4 compared to the commercial crystalline glaze containing a similar fraction of micrometer commercial zircon.
\end{abstract}

Keywords: Ceramic glaze; Nanocomposites; Mechanical properties; Wear resistance; Optical properties 


\section{Introduction}

An economically relevant aspect of the ceramic companies is the optimization and improvement of the opacity as well as mechanical properties (mostly wear resistance) in glazes $^{1-4}$. Specially, a relevant problem of manufacturers is the wear and tear that occurs in glazes ${ }^{5,6}$. To overcome this faulty behaviour, it is customary to introduce particles with higher toughness into the frits to avoid detachment and thus, improving the wear resistance. Presently, one of the most widespread additives in the composition of glazes is the zirconium silicate (zircon) because its relatively low cost (it is a natural silicate) and its performance, such as higher scratch hardness, stability against temperature changes of firing, chemical stability and higher wear resistance, better than other additives traditionally used ${ }^{7}$. Zircon is usually incorporated directly in the formulation of ceramic frits before firing, but it can also be synthesized "in situ" by adding zirconia in the composition of the silica based frit during the thermal treatment. This mineral has a high melting point ${ }^{5,8,9}$ and it is used to increase the wear resistance, impact resistance, thermal shock and chemical attack of the glaze. However, due to rising prices in the market and potential supply problems, the current tendency is to decrease the amount of this substance or even to replace it by other less expensive materials, ${ }^{10-12}$.

Opacification is another highly sought after property in the manufacture of ceramic glazes. Due to its high refractive index, zirconia and milled or micronized zircon are used as opacifier for tile glazes and porcelain enamels ${ }^{13,14}$. Particle size is also a relevant factor to take into account in the opacification of glazes. The smaller the particle size of zircon is, the greater the opacity will be obtained. The fraction of zircon added to the frit to achieve a good opacified level differs according to different authors (8-20 wt.\%) $)^{13,15}$ 
In the present work, metastable tetragonal zirconia phase nanoparticles have been synthesized on sepiolite fibers to avoid coalescence and agglomeration.

We propose a new safe method to introduce zirconia nanoparticles in a commercial ceramic frit and to obtain a multifunctional new ceramic glaze with zircon single crystals, which increase the mechanical properties, opacity as well as wear resistance of the original crystalline frit.

\section{Experimental procedure}

Natural sepiolite mineral from Vicalvaro-Vallecas (Tolsa, Spain) has been purified and micronized by a wet process to obtain a final product more than $95 \%$ content of sepiolite. The sepiolite needle-like particles have a length ranging from 0.2 to $2 \mu \mathrm{m}$ and a thickness of 20-100 nm. Structural channels of $0.5 \mathrm{~nm} \times 1.1 \mathrm{~nm}$ extend all along the long dimension of the fibers. Zirconia nanoparticles were obtained following the synthesis process described in a previous work ${ }^{16}$ using $\mathrm{ZrOCl}_{2} \cdot 8 \mathrm{H}_{2} \mathrm{O}$ as reagent. Nanoparticles were shyntesized adjusting $\mathrm{NaOH}$ to stabilize the $\mathrm{pH}$ of the suspension at $\mathrm{pH} 8$ in order to precipitate the corresponding metal hydroxide into the octahedral position of lixiviated magnesium ${ }^{17}$. The obtained precursor was calcined at $900^{\circ} \mathrm{C}$ for $2 \mathrm{~h}$ in air and the final concentration of zirconia in sepiolite was $50 \mathrm{wt}$. \%. The obtained zirconia nanoparticles remained in a stable tetragonal phase.

The sepiolite- $\mathrm{ZrO}_{2}$ calcined at $900{ }^{\circ} \mathrm{C}$ powder was subsequently mixed with a commercial ceramic frit (15 wt.\%) in an agate mortar. Pellets from the powder were obtained by uniaxial pressing at $50 \mathrm{MPa}$ and were heated at $1220^{\circ}$ for $5 \mathrm{~min}$ to become in a glaze. 
The composition of the frit used was: 66,87 wt. $\% \mathrm{SiO}_{2}, 0,07$ wt. $\% \mathrm{Fe}_{2} \mathrm{O}_{3}, 10,99$ wt. \% $\mathrm{ZnO}, 3$ wt. $\% \mathrm{MgO}, 0,02$ wt. $\% \mathrm{Na}_{2} \mathrm{O}, 5$ wt. $\% \mathrm{Al}_{2} \mathrm{O}_{3}, 1,98$ wt. $\% \mathrm{~K}_{2} \mathrm{O}$, and 11,97 wt.\% $\mathrm{CaO}$.

Commercial frit samples with and without zircon (Zircomin, Colorobia, Spain) were used as reference to study the mechanical, optical and wear behaviour. An equivalent zircon quantity (11 wt.\%) was used taken into account the quantity of zirconia in sepiolite.

Samples have been labelled as follows: Fr for commercial frit, FZr for frit with commercial zircon and FSZr for frit with sepiolite- $\mathrm{ZrO}_{2}$. Solid samples were polished with $1 \mu \mathrm{m}$ abrasive diamond paste, to obtain a flat surface to make the wear test. Wear resistance of materials was studied by using a "ball-on-disk" type wear test under ambient dry conditions in a Microtest tribometer (model MT/60/NI) in conformity with ASTM G99, using alumina balls ${ }^{18-20}$. The applied load $\left(\mathrm{F}_{\mathrm{N}}\right)$ was $6 \mathrm{~N}$ and tests lasted 10 $\mathrm{h}$, which corresponded to a sliding distance $(\mathrm{S})$ of $1500 \mathrm{~m}$. Pellets were introduced in an epoxy resin, and then they were cut into plates to make XRD diffraction. X-ray diffraction patterns were recorded in a Bruker D8 diffractometer using $\mathrm{CuK} \alpha$ radiation. Transmission electron microscopy (TEM) images were taken by a JEOL microscope model FXII operating at $200 \mathrm{Kv}$. Scanning electron microscopy Nova тM NanoSEMFEI Company was used for the observation of microstructures of zircon particles and worn surface of the samples. UV-Vis diffuse reflectance measurement was performed on rough surfaces by a Jasco v-660 (Tokyo, Japan) spectrophotometer with a diffuse reflectance attachment. Reflective index measurements were recorded on optically polished surfaces by an Sopra GES-5E ellipsometer equiped with a spectrometer and a photomultiplier operative in the range from 200 to $850 \mathrm{~nm}$ lightened with a xenon short arc lamp, at an incidence angle of $75^{\circ}$. The Vickers hardness, $\mathrm{H}_{\mathrm{V}}$, of the samples was 
determined by microindentation (Buehler model Micromet 5103) on samples surfaces polished down to 1 micron, applying a $1.96 \mathrm{~N}$ load with an indentation time of $10 \mathrm{~s}$. The magnitude of the Vickers hardness was determined according to,

$$
H_{V}=1.854 \frac{P}{d^{2}}
$$

where $P$ is the applied load $(\mathrm{N})$ and $d$ is the diagonal length $(\mathrm{m})$.

The fracture toughness was also determined by microindentation, but for this specific property, the applied load was $4.9 \mathrm{~N}$ with an indentation time of $10 \mathrm{~s}$. The fracture toughness was calculated using the formula given by Miranzo and Moya ${ }^{21}$

In order to estimate correctly the volume losses, the track profiles were analysed with a surface profilometer (Talysurf CLI 500, Taylor Hobson, Leicester, UK) that maps the surface by putting a stylus in mechanical contact with the sample. The stylus arm has $90^{\circ}$ conisphere diamond styli with $2 \mu \mathrm{m}$ nominal radius tip. The data sampling interval in $\mathrm{X}$ and $\mathrm{Y}$ was $0.5 \mu \mathrm{m}$ and $2.5 \mu \mathrm{m}$ respectively. The resolution (Z) was $32 \mathrm{~nm}$. The profilometer was used to determine the three-dimensional surface topographic maps, so track volumes were estimated and, hence, Eq. (2) could be applied.

$$
W=\frac{\Delta V}{F_{N} S}
$$

Being $\mathrm{W}$ the wear rate $\left(\mathrm{mm}^{3} / \mathrm{Nm}\right), \Delta V$ the volume loss after the tests $\left(\mathrm{mm}^{3}\right), F_{N}$ the applied load (N) and $S$ the sliding distance (m). 


\section{Results}

The X-ray diffraction pattern corresponding to sepiolite powder, sepiolite- $\mathrm{ZrO}_{2}$ and sepiolite- $\mathrm{ZrO}_{2}$ calcined at $900^{\circ} \mathrm{C}$ are shown in Figure 1 . As it can be observed, only sepiolite diffraction peaks (Fig.1a) appear in the sepiolite- $\mathrm{ZrO}_{2}$ precursor sample (Fig.1b). However, when this sample was heated at $900^{\circ} \mathrm{C}$ the $\mathrm{t}-\mathrm{ZrO}_{2}$ diffraction peaks are present (Fig.1c). The peaks corresponding to tetragonal zirconia are quite broad, indicating that zirconia particles have a nanostructured character.

The morphology and the particle size distribution of the samples were studied by TEM. As observed in Fig.2, in the sample heated at $900^{\circ} \mathrm{C}$, the particle size distribution seems to be bimodal, probably due to the high zirconia concentration in the fibers (50 wt. \%), where original $\sim 7 \mathrm{~nm}$ zirconia nanoparticles coexist with large agglomerates $(\sim 20 \mathrm{~nm})$. The X-ray diffraction patterns of the obtained glazes are shown in Fig. 3. As it can be seen in Figure 3a, the Fr sample presents no peaks as it corresponds to glassy phase. In the case of FZr and FSZr samples, zircon peaks appear (Fig. 3b and 3c respectively). The absence of peaks of zirconia (tetragonal or monoclinic phase) indicates that zirconia particles reacted with silica to form zircon during firing. A small amount of calcium silicate (wollastonite) also appears.

The size, shape and distribution of zircon particles can be observed by SEM (Fig. 4). The surface of the samples was previously treated with diluted HF to obtain a clearer morphology of the particles. Figure 4 shows that zircon single crystals formed in situ by introducing sepiolite- $\mathrm{ZrO}_{2}$ in the commercial frit (Fig. 4a-b), have a narrower size distribution than the FZr sample with incorporated commercial zircon (Fig. 4c-d). In contrast with the irregular shape from zircon particles of FZr sample, these particles show a needle-like shape with a dimension of 1-2 $\mu \mathrm{m}$ length and 200-300 nm width. 
Figure 5 shows the surface topography of the three-dimensional wear tracks for all materials studied after sliding against pure alumina ball. From the 3D wear track surface topographies, the corresponding wear rate, was estimated and summarized in Table I. In both Fr (Fig. 5a) and FZr samples (Fig. 5b) the wear track depth is similar, but much higher than in the FSZr sample (Fig. 5c), indicating a higher removed volume. The wear rate of FSZr sample decreases down to four times compared to the wear rate of glaze with commercial zircon (FZr) and commercial frit (Fr) (Fig 5d).

The worn surface of the samples was studied by SEM in order to determine the operating wear mechanism. In Fr (Fig.6a) and FZr (Fig. 6b) samples, pull out and material detachment from glaze were observed in a large area of worn surface. The formation of a large number of cracks and sharp edges can be observed. FSZr sample presented a different worn surface (Fig. 6c). A relatively smooth region was observed and no microcracks or microfractures were found at the contact surface. Moreover, it can be observed a good distribution of zircon particles in the entire surface, which is an important factor affecting the wear rate of this glaze.

In Figure $7 \mathrm{a}$, hardness increases corresponding to the containing $11 \%$ zircon with respect to the crystalline glaze, can be observed. Fr glaze has a Hv value of $5.7 \mathrm{GPa}$, while the hardness value for glaze containing zircon increases up to 6.1 and $6.3 \mathrm{GPa}$ for FZr and FSZr respectively. Toughness value $\left(\mathrm{K}_{\mathrm{IC}}\right)$ also increases with the incorporation of zircon to a glaze. In the particular case of the zircon formed during firing, a higher toughness value and less dispersion in the measures $\left(\underline{\left.0.9 \pm 0.09 \mathrm{MPa} \cdot \mathrm{m}^{1 / 2}\right)}\right.$ than for the commercial zircon addition case $\left(\underline{0.7 \pm 0.18} \mathrm{MPa}^{1 / 2}\right)$ is obtained (Fig $\left.7 \mathrm{~b}\right)$.

The optical properties of the studied samples are reported in Table II. The largest L* value, that represents the brightness or whiteness in CIELAB color space, corresponds with FSZr sample with a value of 94.05 while samples FZr and Fr have values of 90.05 
and 67.71 respectively. Finally, reflective measurements report a notable increase of the reflective index (at $\lambda=500 \mathrm{~nm}$ ) for the FSZr sample $\mathrm{n}=1.5887$ in respect to the one corresponding to transparent frit Fr $n=1.5287$. Just for comparison sake, the refractive index corresponding to frit with zircon $\mathrm{FZr}$ presents a value of $\mathrm{n}=1.573$.

\section{Discussion}

It is well known that a good zircon dispersion improves opacification ${ }^{8,15}$, mechanical properties and wear resistance of the glazes ${ }^{22}$. We have herewith used sepiolite as a carrier to support and disperse zirconia nanoparticles and then to introduce them in a glassy matrix to obtain a glaze. Sepiolite plays an important role in the distribution of the particles and thereby avoids coalescence. Particles are embedded into sepiolite fibers avoiding the growth of particles even at high temperature. Moreover sepiolite provides the required silica to react with zirconia nanoparticles forming dispersed needle-like shaped zircon single crystals network with a homogenous size ${ }^{17}$. This raw material in turn, can be mixed with a frit and thus obtain a good dispersion of particles when sepiolite is dissolved in the glaze. Particles of zirconia react in the firing cycle at $1220^{\circ} \mathrm{C}$ with silica that belong to sepiolite and/or frit, to form zircon with the same distribution as zirconia. The presence of a small fraction of wollastonite and zircon in the glaze can be rationalized considering the $\mathrm{SiO}_{2}-\mathrm{ZrO}_{2}-\mathrm{CaO}$ equilibria diagram ${ }^{23}$ and assuming for simplicity reasons, $\mathrm{Na}_{2} \mathrm{O}, \mathrm{K}_{2} \mathrm{O}, \mathrm{MgO}$, and $\mathrm{ZnO}$ in $\mathrm{CaO}$. Obviously, the real temperature of the peritectic corresponding to cristoballite-zircon-wollastonite of this ternary system $\left(1436^{\circ} \mathrm{C}\right)$ in our multicomponent glaze must be significantly lower. Then, the presence of wollastonite at $1220^{\circ} \mathrm{C}$ is thus feasible. In the case of the $\mathrm{FZr}$ sample, the hardness value also increases with respect to the frit and it was similar to the FSZr sample, 
although the standard deviation is higher. Dispersion is an important factor in hardness, because a bad dispersion would produce a gradient in the hardness values. Similarly, toughness also increases in both, but it increases twice in the case of sample FSZr. This is most likely due to their needle-like shape zircon particles network.

The evolution of the loss volume values corresponding to wear test for Fr and FZr samples suggests that the wear mechanism in both materials seems to be similar. The worn surface shows evidence of cracking and pullout (Fig 6). Oppositely the wear rate and the wear mechanism in the FZr and FSZr samples which have the same amount of zircon are totally different. Better dispersion and needle-like shape zircon single crystal grains in the FSZr sample result in higher values for both toughness and hardness, with a lower statistical dispersion, preventing to a greater extent the formation and propagation of cracks in the material. In this sense, the main operating wear mechanism is abrasion which is consistent with the data obtained from wear rate (Table I). Sample FZr has a higher toughness than crystalline glaze in located areas, but the formation of cracks is not inhibited due to uneven distribution of zircon particles, and thus these are formed and propagated through glass brittle matrix material. Because of this, the formation of microcracks in wear track facilitates the removal of material and therefore increases wear rate with respect to FSZr sample.

Opacification is determined by small particles light scattering. In this regard, Rayleigh scattering regime, which corresponds to particles much smaller than the wavelength is the optimal one. Moreover, this scattering increases with the square power of the refractive index contrast ${ }^{24}$. In this sense, zircon and preferentially zirconia, which have very large refractive indices ( $n=1.94$ and 2.16 respectively) and a small particle size become very efficient scatter centres and consequently good opacification agents. In addition to whitening or opacification, the inclusion of zirconia and zircon particles is 
able to raise the effective refractive index, and consequently the reflection coefficient. Refractive index measurements reported in Table II show that the FSZr sample presents the largest increase of the refractive index in comparison with that of the frit (larger refractive index implies larger reflectivity), which suggests that this opacification method produces zircon and/or zirconia particles perfectly embedded into the glassy frit without bubbles, cracks or any other imperfections which could reduce the effective refractive index,. The CIELAB luminance labelled as $L^{*}$, the parameter which takes into account the diffuse reflecting power, increases for larger values of $n$. FSZr sample presents a very high $L^{*}$ value and better than the commercial containing zircon glazes. Consequently, it can be inferred that Sepiolite- $\mathrm{ZrO}_{2}$ sample introduce a larger added value than the one containing commercial zircon, or even higher than other glazes reported in literature with similar zircon content ${ }^{15,25}$.

\section{Conclusions}

The following conclusions can be drawn:

- It has been proved that by the addition $(15 \mathrm{wt} \%)$ of sepiolite- $\mathrm{nZrO}_{2}(50 \mathrm{wt} \%)$ to a commercial transparent ceramic frit, an arrangement of needle-like zircon single crystal $(\sim 1 \mu \mathrm{m})$ is formed in-situ during the firing cycle at $1220^{\circ} \mathrm{C}$.

- The wear rate of the obtained glaze was found to be $\sim 4$ times lower than the one corresponding to a conventional glaze with a similar fraction $(\sim 11 \mathrm{wt} \%)$ of zircon sand.

- The toughness $\left(\mathrm{K}_{\mathrm{IC}}\right)$ of the obtained glaze $\left(\underline{\left.0.9 \pm 0.09 \mathrm{MPa} \cdot \mathrm{m}^{1 / 2}\right)}\right.$ was found to be almost twice the one corresponding to commercial transparent one $\left(\underline{\left.0.5 \pm 0.08 \mathrm{MPa} \cdot \mathrm{m}^{1 / 2}\right)}\right.$.

- The $\mathrm{L}^{*}$ values (opacity) and reflectivity of the obtained glaze was found to be 94 vs 90 for the frit with commercial zircon. 


\section{Acknowledgements}

This research has been supported by the Spanish Ministry of Science and Innovation under project DOMINO (CENIT-2007-1001).

\section{References}

1 Karasu B, Dölekcekic E, Özdemir B. Compositional Modifications to Floor Tile Glazes Opacified with Zircon. British Ceramic Transactions 2001, 100:81-85.

${ }^{2}$ Teixeira S, Bernardin AM. Development of $\mathrm{TiO}_{2}$ white glazes for ceramic tiles. Dyes and Pigments 2009, 80:292-296

${ }^{3}$ Montazerian M, Alizadeh P, Eftekhari Yekta B, Processing and properties of a micaapatite glass-ceramic reinforced with Y-PSZ particles. Journal of the European Ceramic Society 2008, 28:2693-2699.

${ }^{4}$ Bijan Eftekhari Yekta, Parvin Alizadeh, Leila Rezazadeh, Floor tile glass-ceramic glaze for improvement of glaze surface properties. Journal of the European Ceramic Society 2006, 26:3809-3812.

${ }^{5}$ Llusar M, Rodrigues C, Labrincha J, Flores M, Monrós G, Reinforcement of singlefiring ceramic glazes with the addition of polycrystalline tetragonal zirconia (3Y-TZP). Journal of the European Ceramic Society 2002, 22:639-652.

${ }^{6}$ Llusar M, Monrós G, Rodrigues CM, Labrincha JA, Study of Zircon or ZirconiaInduced Opacification of Glazes by Impedance Spectroscopy, Ceramics International 2005, 31:181-188.

${ }^{7}$ Parmelee CW, Ceramic Glazes 3rd Revised edition:C. Books, Boston 1973. 
${ }^{8}$ Castilone RJ, Sriram D, Carty WM, Snyder RL, Crystallization of zircon in stoneware glazes. Journal of the American Ceramic Society, 1999, 82:2819-2824.

${ }^{9}$ Aksel C, The influence of zircon on the mechanical properties and thermal shock behaviour of slip-cast alumina-mullite refractories. Materials Letters 2002, 57:992-997.

${ }^{10}$ Pekkan K, Karasu B, Zircon-free frits suitable for single fast-firing opaque wall tile glazes and their industrial productions. Journal of the European Ceramic Society 2009, 29:1571-1578.

11 Biffi G, Ortelli G, Vincenzini P, Ceramic glazes opacified with $\mathrm{CaTiSiO}_{5}$. Ceramurgia International 1975, 1:34-35.

12 Cavalcante P.M.T., Dondi M., Guarini G., Raimondo M., Baldi G., Colour performance of ceramic nano-pigments. Dyes and Pigments 2009, 80:226-232.

${ }^{13}$ Avgustinik A. I., Cerámica, $2^{\circ}$ ed. Barcelona: Reverte; 1983.

14 Jacobs CWF, Opacifying Crystalline Phases Present in Zirconium-Type Glazes. Journal of the American Ceramic Society 1954, 37:216-220.

${ }^{15}$ Snyders E, Potgieter JH, Nel JT, The upgrading of an inferior grade zircon to superior opacifier for sanitary ware and glazes. The Journal of The South African Institute of Mining and Metallurgy 2005, 105:459-464.

${ }^{16}$ Pecharroman C, Esteban-Cubillo A, Montero I, Moya JS, Aguilar E, Santaren J, Alvarez A, Monodisperse and Corrosion-Resistant Metallic Nanoparticles Embedded into Sepiolite Particles for Optical and Magnetic Applications. Journal of the American Ceramic Society 2006, 89:3043-3049.

${ }^{17}$ Esteban-Cubillo A, Pina-Zapardiel R, Moya JS, Barba MF, Pecharroman C, The role of magnesium on the stability of crystalline sepiolite structure. Journal of the European Ceramic Society 2008, 28:1763-1768. 
18 Rodriguez-Suarez T, Bartolomé JF, Smirnov A, Lopez-Esteban S, Torrecillas R, Moya, JS. Sliding wear behaviour of alumina/nickel nanocomposites processed by a conventional sintering route. Journal of the European Ceramic Society 2011,31:13891395.

19 Rodriguez-Suarez T, Bartolomé JF, Smirnov A, Lopez-Esteban S, Díaz LA, Torrecillas R, Moya JS. Electroconductive Alumina-TiC-Ni nanocomposites obtained by Spark Plasma Sintering. Ceramics International 2011,37:1631-1636.

${ }^{20}$ Rodriguez-Suarez T, Bartolomé JF, Moya JS. Mechanical and Tribological properties of ceramic/metal composites: a review of phenomena spanning from the nanometer to the micrometer length scale. Journal of the European Ceramic Society 2012, 32:38873898.

${ }^{21}$ Miranzo P, JS Moya, Elastic/plastic indentation in ceramics: a fracture toughness determination method, Ceramics International 1984, 10:147-152.

${ }^{22}$ Sánchez E, García-Ten J, Sanz V, Moreno A, Porcelain tile: Almost 30 years of steady scientific-technological evolution, Ceramics International 2010, 36:831-845.

${ }^{23}$ Phase Equilibria Diagrams CD-ROM Database (NIST Standard Reference Database 31), Version 3.4, The American Ceramic Society and the National Institute of Standards and Technology, 2012.

${ }^{24}$ Hulst HC, Light scattering by small particles, New York:Wiley; 1957.

${ }^{25}$ Wilson PJ, Blackburn S, Greenwood RW, Prajapti B, Smalley K, The role of zircon particle size distribution, surface area and contamination on the properties of silicazircon ceramic materials. Journal of the European Ceramic Society 2011, 31:1849-1855. 


\section{FIGURE CAPTIONS}

Fig. 1. XRD powder patterns corresponding to: a) Sepiolite, b) Sepiolite- $\mathrm{ZrO}_{2}$ precursor, and c) Sepiolite $-\mathrm{ZrO}_{2}$ calcined at $900^{\circ} \mathrm{C}$. Arrows show the peaks of tetragonal zirconia phase.

Figure 2. TEM micrographs of sepiolite with zirconia sample calcined at $900^{\circ} \mathrm{C}$ with different magnifications.

Figure 3. XRD patterns corresponding to: a) Fr, b) FZr and c) FSZr glazes. Circle and arrows show wollastonite and zircon peaks respectively.

Figure 4. SEM micrographs showing the microstructure of the samples containing zircon after chemical attack with HF: a) FSZr, b) close up of the zircon single crystals in FSZr, c) FZr and d) close up of the zircon commercial particles in FZr.

Figure 5. Wear track 3D image provided by profilometer in: a) Fr, b) FZr, and c) FSZr samples. Wear rate of the different glazes is shown in figure d).

Figure 6. SEM micrographs corresponding to the worn surface of: a) Fr, b) FZr and c) FSZr samples.

Figure 7. Vickers hardness (a) and fracture toughness (b) of glazes. 


\section{TABLE CAPTIONS}

Table I. Volume loss and wear rate values (W) obtained for Fr,FZr and FSZr when slid against pure alumina ball ( $\mathrm{S}=1500 \mathrm{~m}, \mathrm{~F}_{\mathrm{N}}=6 \mathrm{~N}, \mathrm{~V}=180$ r.p.m. $)$.

Table II.Optical properties of samples. $\mathrm{L}^{*}$ : stands for luminance, $\mathrm{n}$ : refractive index and $\mathrm{R}$ : normal specular reflectance. 


\section{TABLES}

\begin{tabular}{ccc}
\hline Sample & $\Delta$ volume $\left(\mathbf{m m}^{\mathbf{3}}\right)$ & $\begin{array}{l}\text { Wear rate } \\
(\mathbf{m m} / \mathbf{N m})\end{array}$ \\
\hline Fr & 0.40 & $4.90 \mathrm{E}-05$ \\
FZr & 0.35 & $4.32 \mathrm{E}-05$ \\
FSZr & 0.10 & $1.25 \mathrm{E}-05$ \\
\hline
\end{tabular}

Table I. Volume loss and wear rate values (W) obtained for Fr,FZr and FSZr when slid against pure alumina ball $\left(\mathrm{S}=1500 \mathrm{~m}, \mathrm{~F}_{\mathrm{N}}=6 \mathrm{~N}, \mathrm{~V}=180\right.$ r.p.m. $)$.

\begin{tabular}{cccc}
\hline Sample & L* $^{*}$ & $\mathbf{n}$ & $\mathbf{R}(\boldsymbol{\%})$ \\
\hline Fr & 67.71 & 1.5287 & 4.4 \\
FZr & 90.05 & 1.573 & 5.0 \\
FSZr & 94.05 & 1.5887 & 5.2 \\
\hline
\end{tabular}

Table II.Optical properties of samples. $\mathrm{L}^{*}$ : stands for luminance, $\mathrm{n}$ : refractive index and $\mathrm{R}$ : normal specular reflectance 


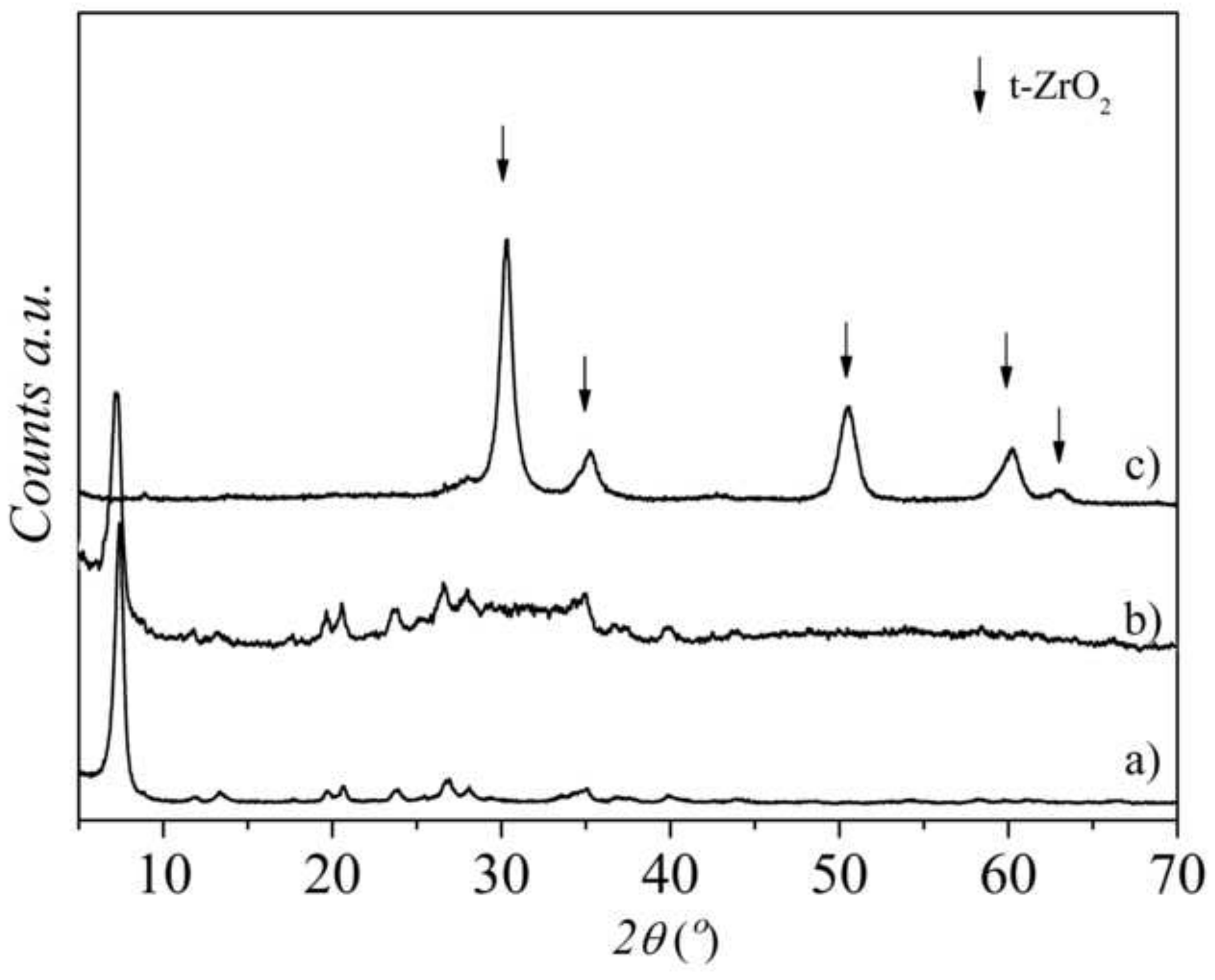



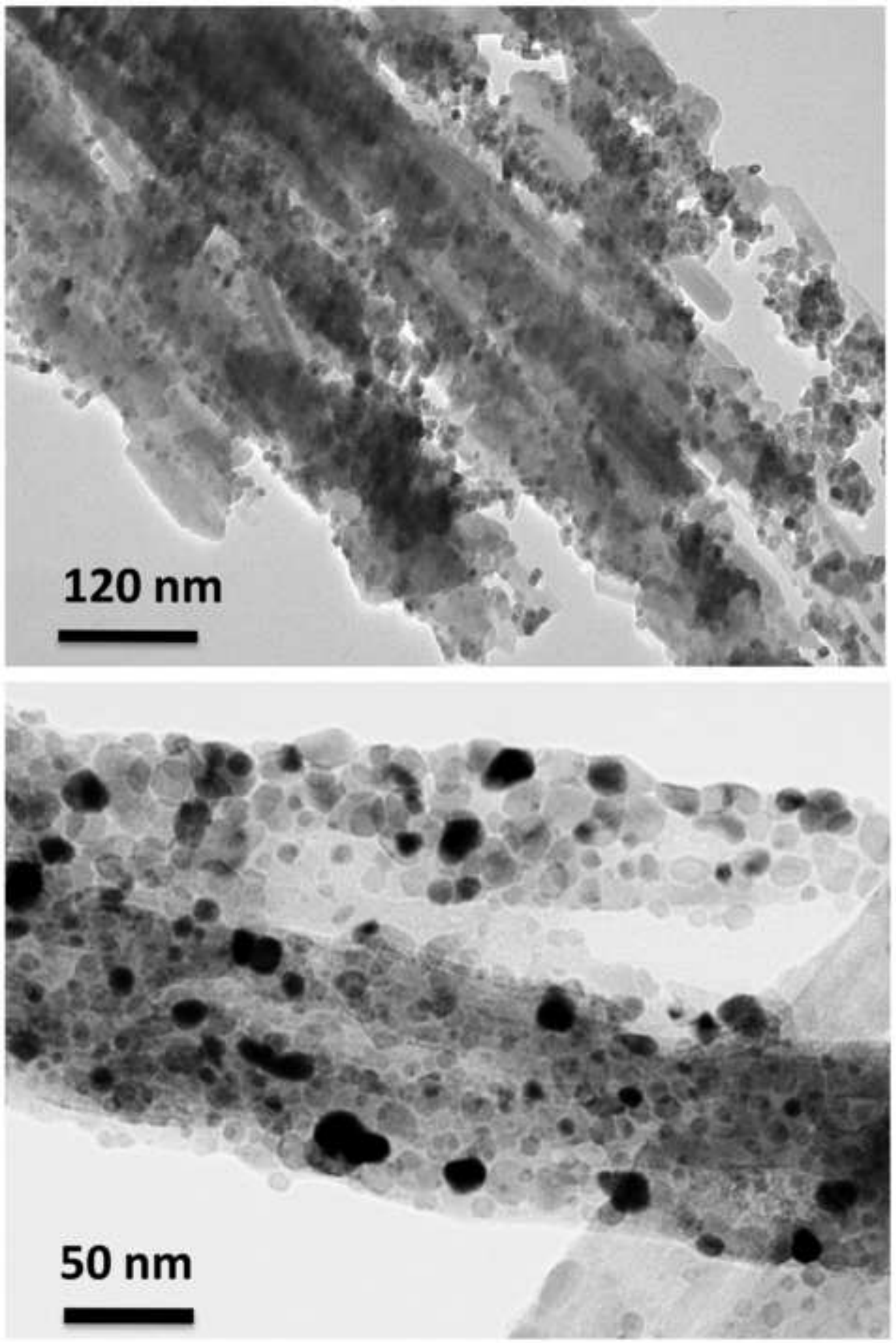


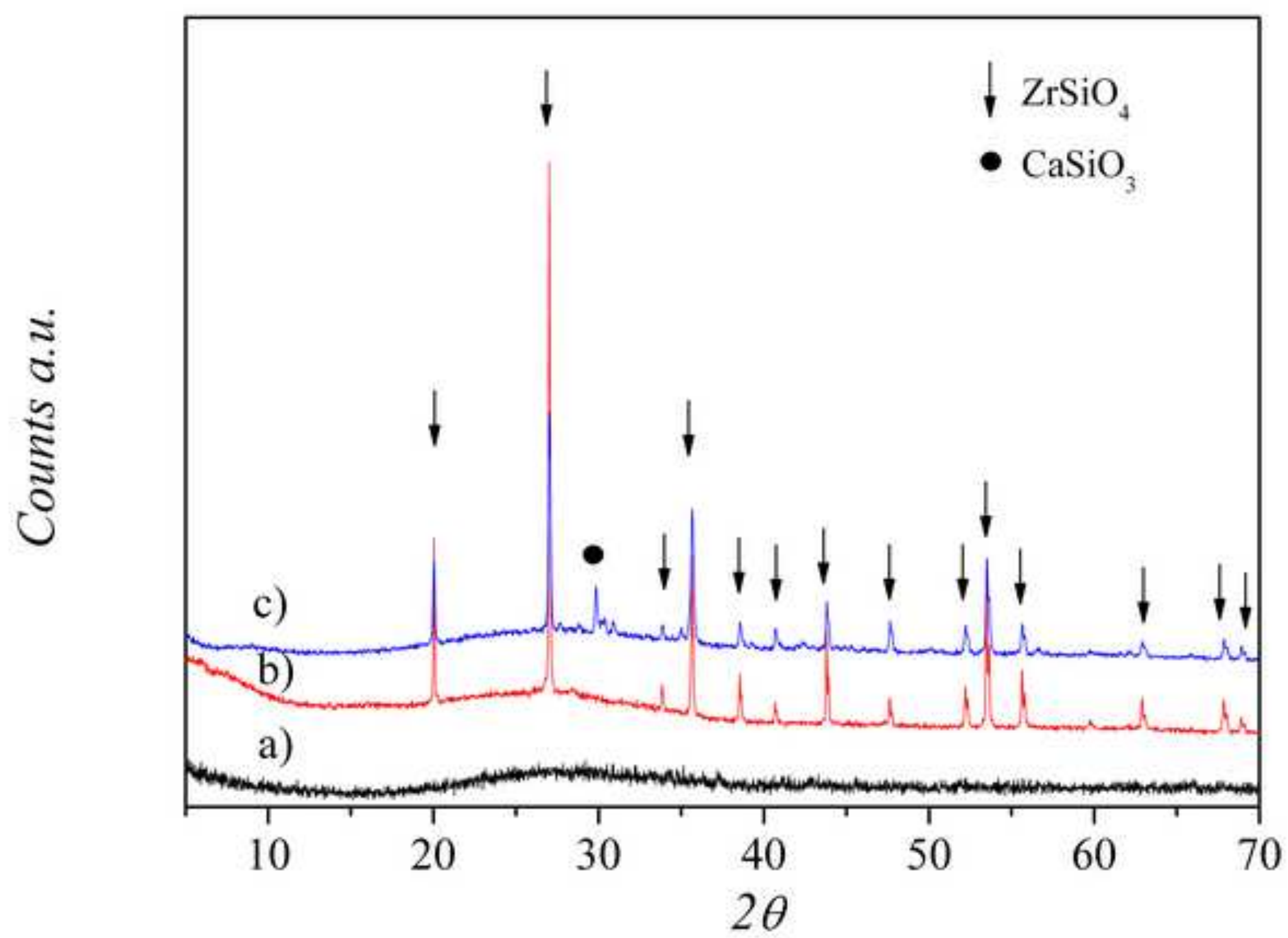




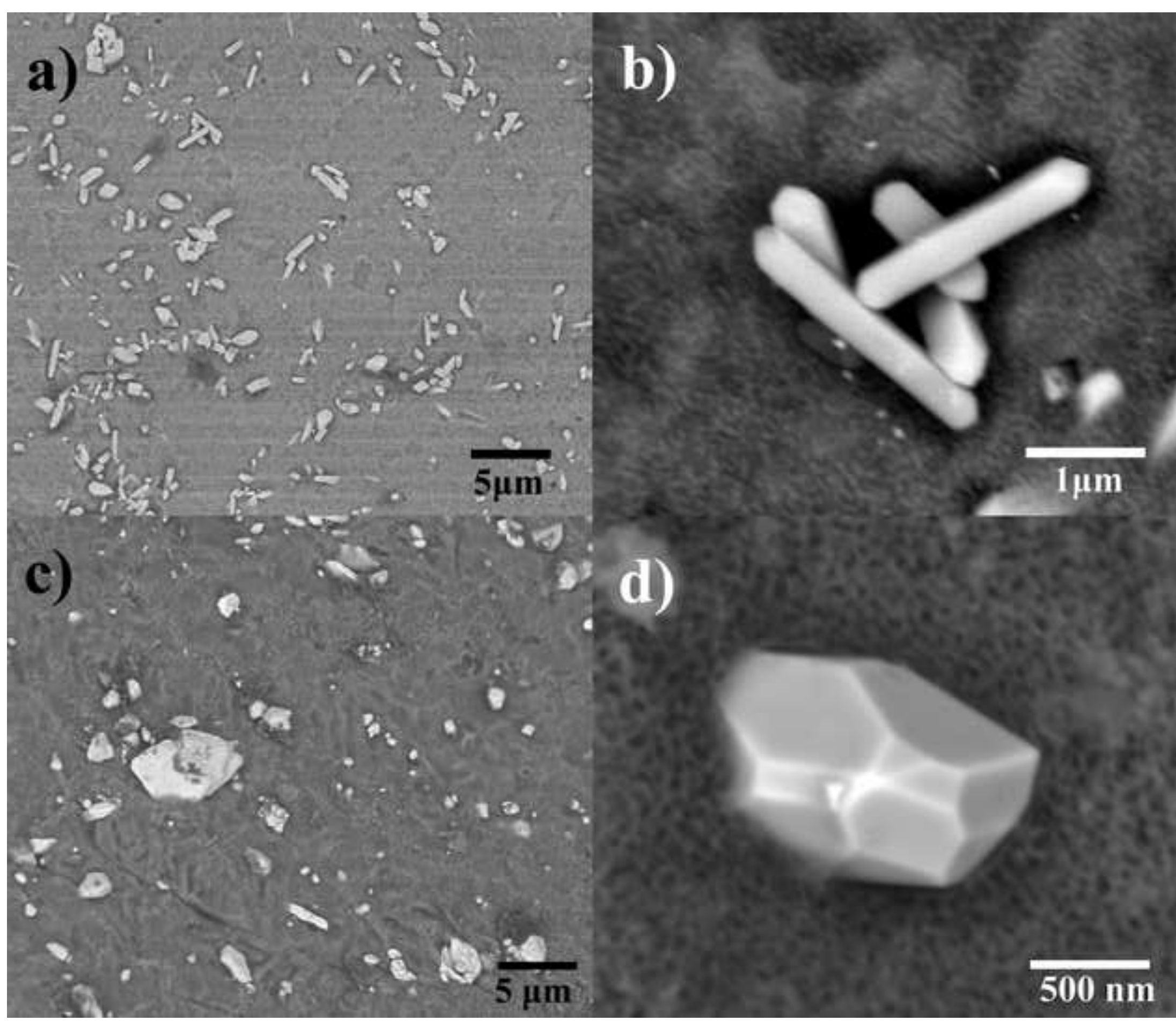

Figure 4
Click here to download high resolution image 
Click here to download high resolution image

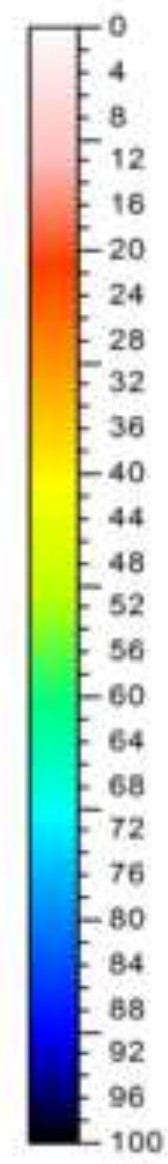
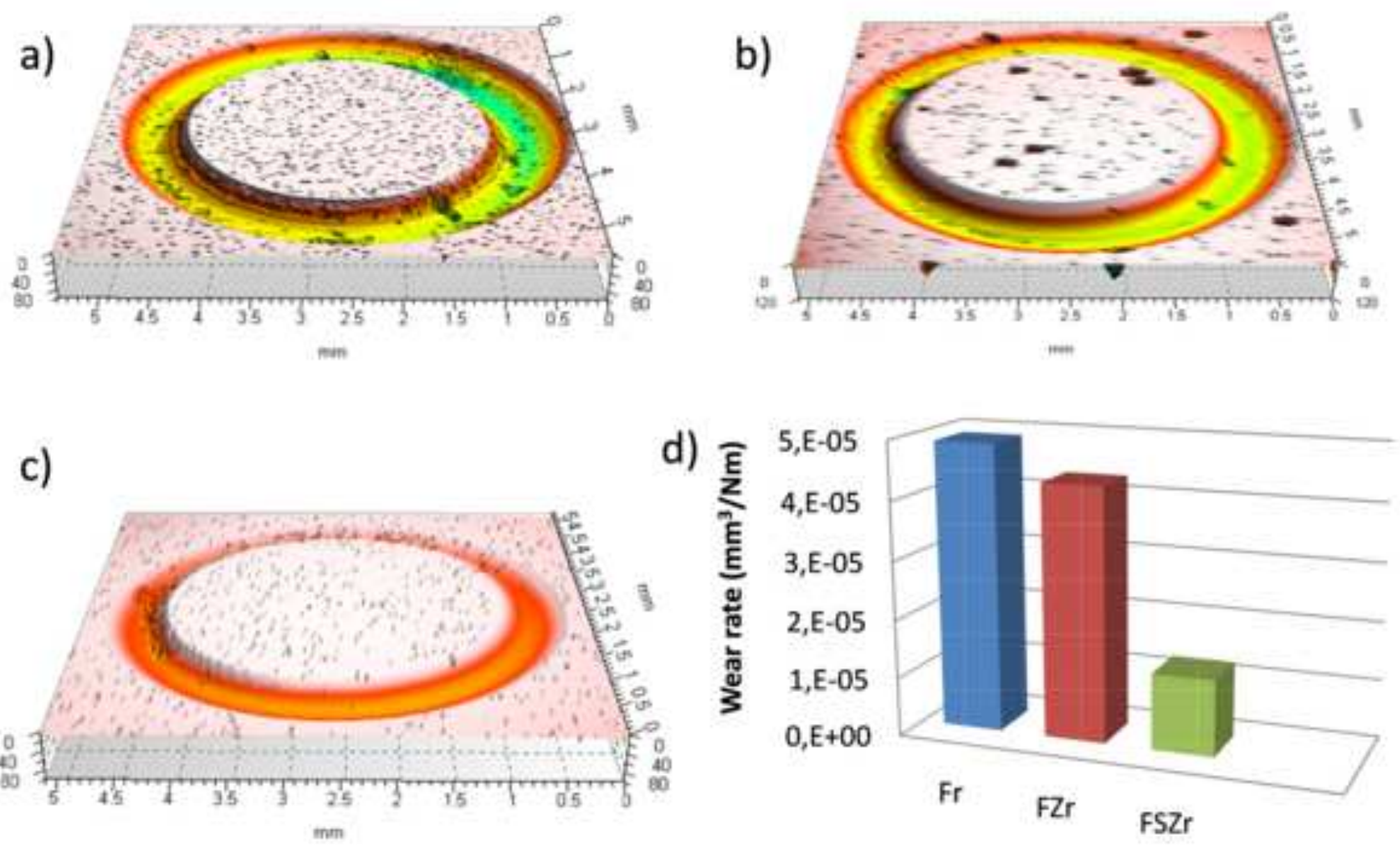

click here to download high resolution image

$4 \mathrm{~m}$

mm 


\section{Click here to download high resolution image}
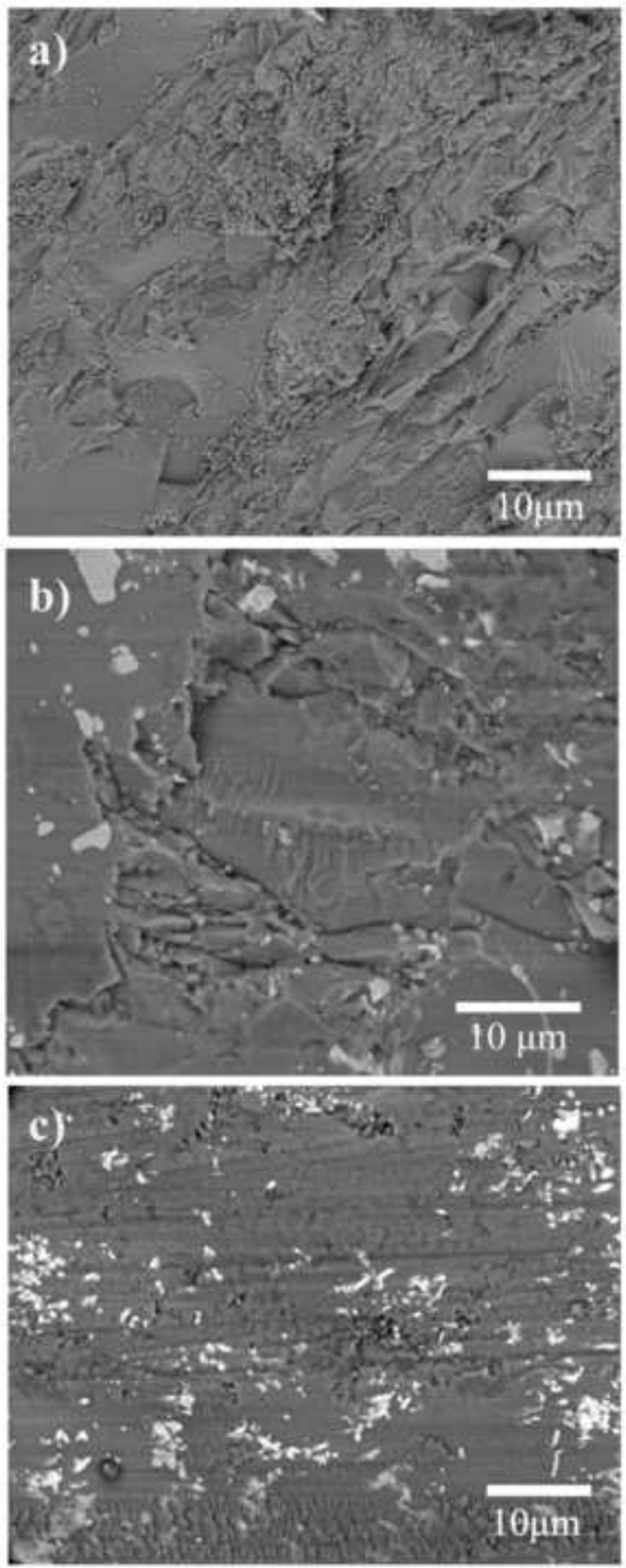
Click here to download high resolution image

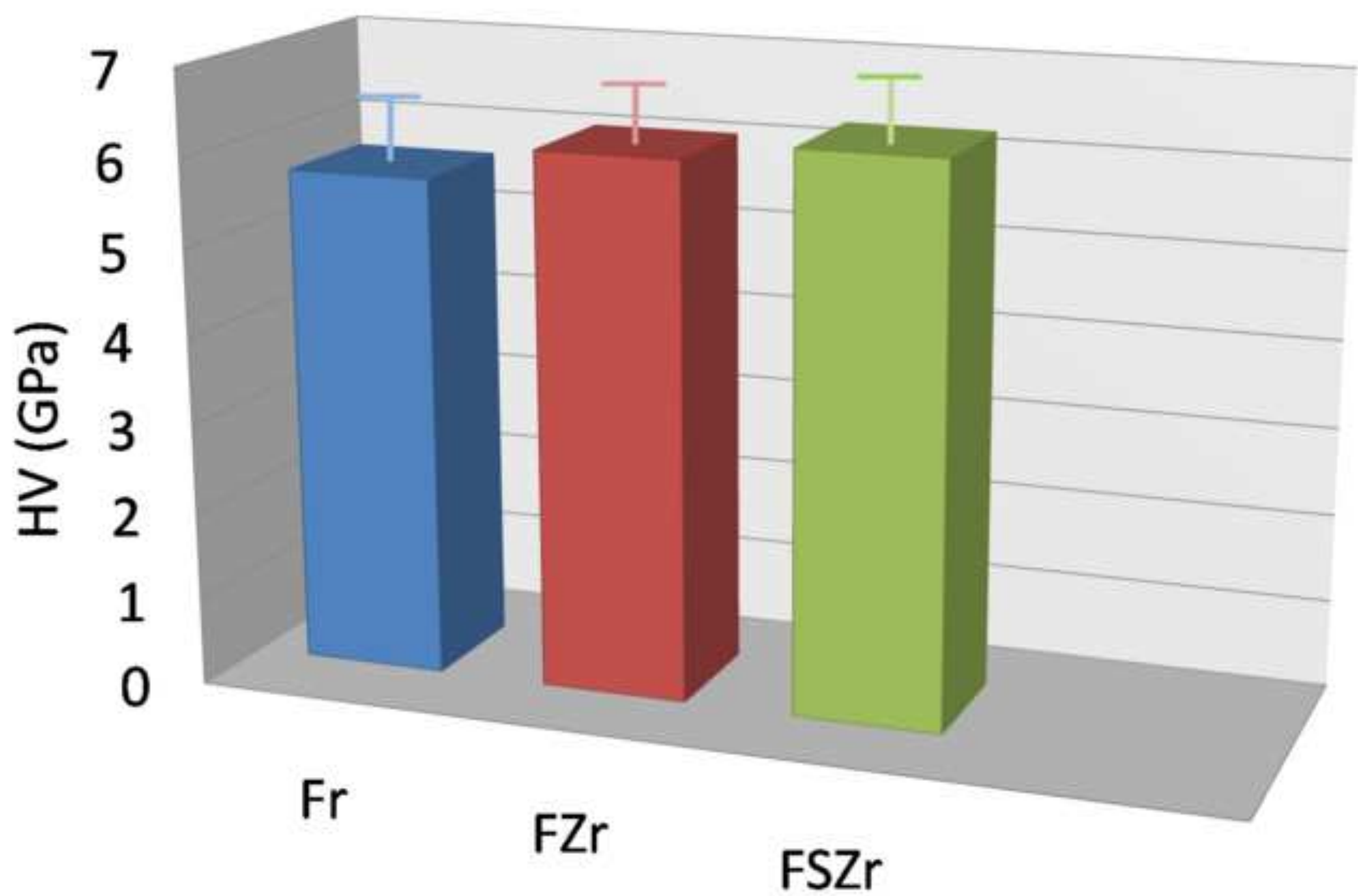

FSZr 


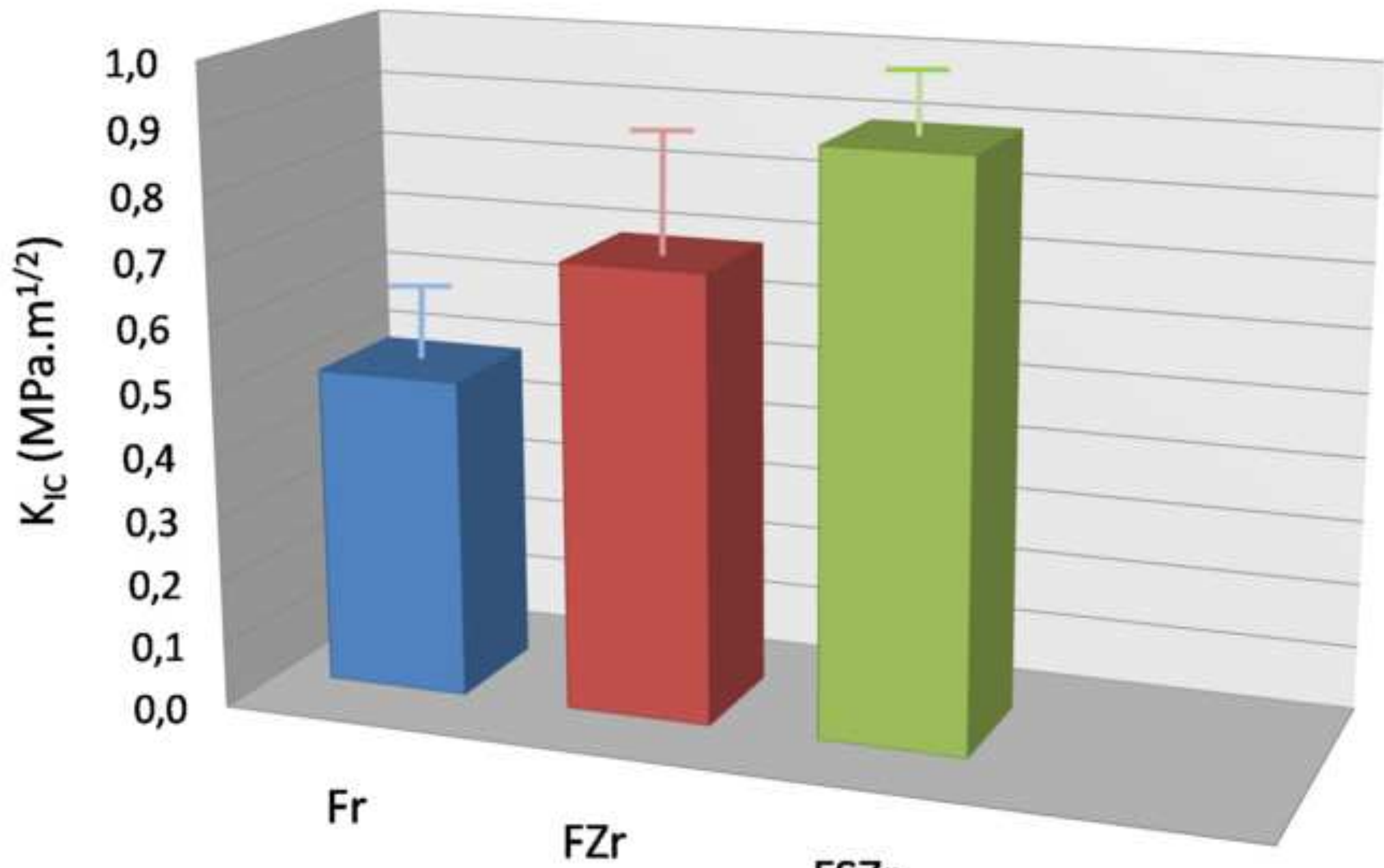

FSZr 